\title{
RESEARCH
}

Open Access

\section{Clean room microbiome complexity impacts planetary protection bioburden}

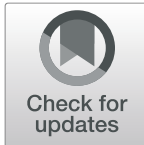

Ryan Hendrickson ${ }^{1}$, Camilla Urbaniak', Jeremiah J. Minich², Heidi S. Aronson' ', Cameron Martino 3,4, Ramunas Stepanauskas ${ }^{5}$, Rob Knight ${ }^{3}$ and Kasthuri Venkateswaran ${ }^{1 *}$ (D)

\begin{abstract}
Background: The Spacecraft Assembly Facility (SAF) at the NASA's Jet Propulsion Laboratory is the primary cleanroom facility used in the construction of some of the planetary protection (PP)-sensitive missions developed by NASA, including the Mars 2020 Perseverance Rover that launched in July 2020. SAF floor samples ( $n=98$ ) were collected, over a 6-month period in 2016 prior to the construction of the Mars rover subsystems, to better understand the temporal and spatial distribution of bacterial populations (total, viable, cultivable, and spore) in this unique cleanroom.
\end{abstract}

Results: Cleanroom samples were examined for total (living and dead) and viable (living only) microbial populations using molecular approaches and cultured isolates employing the traditional NASA standard spore assay (NSA), which predominantly isolated spores. The 130 NSA isolates were represented by 16 bacterial genera, of which $97 \%$ were identified as spore-formers via Sanger sequencing. The most spatially abundant isolate was Bacillus subtilis, and the most temporally abundant spore-former was Virgibacillus panthothenticus. The 165 rRNA genetargeted amplicon sequencing detected 51 additional genera not found in the NSA method. The amplicon sequencing of the samples treated with propidium monoazide (PMA), which would differentiate between viable and dead organisms, revealed a total of 54 genera: 46 viable non-spore forming genera and 8 viable spore forming genera in these samples. The microbial diversity generated by the amplicon sequencing corresponded to $\sim 86 \%$ non-spore-formers and $~ 14 \%$ spore-formers. The most common spatially distributed genera were Sphinigobium, Geobacillus, and Bacillus whereas temporally distributed common genera were Acinetobacter, Geobacillus, and Bacillus. Single-cell genomics detected 6 genera in the sample analyzed, with the most prominent being Acinetobacter.

Conclusion: This study clearly established that detecting spores via NSA does not provide a complete assessment for the cleanliness of spacecraft-associated environments since it failed to detect several PP-relevant genera that were only recovered via molecular methods. This highlights the importance of a methodological paradigm shift to appropriately monitor bioburden in cleanrooms for not only the aeronautical industry but also for pharmaceutical, medical industries, etc., and the need to employ molecular sequencing to complement traditional culture-based assays.

\footnotetext{
* Correspondence: kjvenkat@jpl.nasa.gov

'Biotechnology and Planetary Protection Group, Jet Propulsion Laboratory,

California Institute of Technology, Pasadena, USA

Full list of author information is available at the end of the article
}

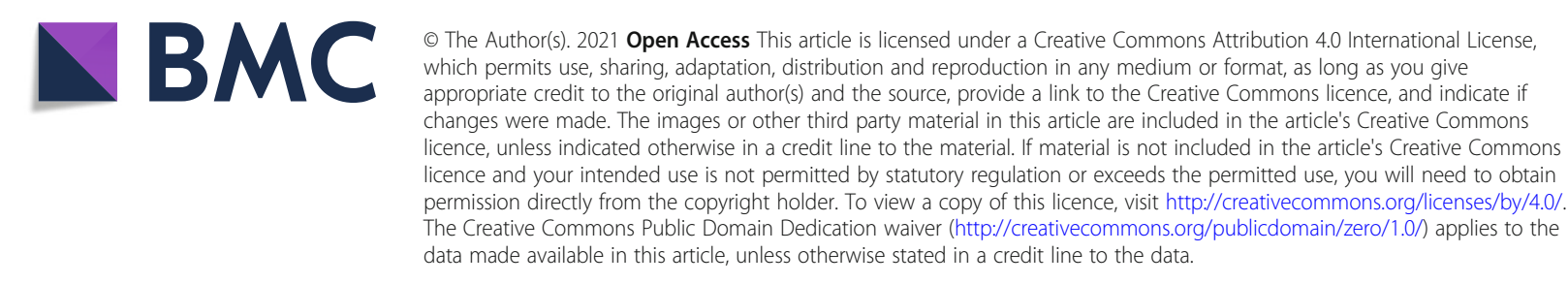




\section{Introduction}

Planetary protection (PP) is a scientific discipline aimed at preventing microbial contamination on spacecraft outbound to a celestial body (forward planetary protection) and on spacecraft hardware and samples returning to Earth (backward planetary protection) to avoid harmful contamination to a native environment or compromising scientific data. While sampling spacecraft surfaces for research purposes is challenging due to extremely low biomass and limited hardware availability, the cleanrooms in which spacecraft is assembled can act as a suitable surrogate for understanding microbial communities related to PP missions [1-6] and identifying microbes that could pose forward contamination risk. The Spacecraft Assembly Facility (SAF) at NASA's Jet Propulsion Laboratory (JPL) is an ISO 8 (Class 100,000) certified cleanroom which has strict environmental controls such as temperature $\left(20 \pm 4^{\circ} \mathrm{C}\right)$, humidity $(30 \pm 5 \%)$, restricted human access, and stringent cleaning regimes [7, 8]. The SAF has been used for many years to assemble various interplanetary spacecraft, including the recently launched Mars 2020 Perseverance rover.

The microbial burden of past PP sensitive spacecraft hardware has been determined through spore detection via the NASA standard assay (NSA), which involves collecting samples using swabs or wipes from surfaces, heat shocking at $80^{\circ} \mathrm{C}$ for $15 \mathrm{~min}$, plating on Tryptic Soy Agar (TSA), and incubating the plates for up to $72 \mathrm{~h}$ at $32^{\circ} \mathrm{C}$ [9-19]. Although the NSA can provide an estimate of biological cleanliness on a spacecraft, the various selective conditions in the NSA method select for a narrow range of aerobic bacteria. Thus, the presence of other spore-formers (i.e., non-NSA spore-formers) and the remaining viable microbial population that are relevant to PP are underestimated $[9,17,20]$. These underestimated microbial populations can be determined via culture-independent molecular methods [21] or approximated using a conversion ratio between the NSA sporeformers and the viable microbial population. This ratio, as outlined by the Space Studies Board (SSB), is 50,000 viable cells for every 1 NSA spore [22]. A recent publication of the SAF cleanroom environment revealed that the ratio of NSA spores to viable microbial cells was in the range of 150 to 12,000 depending on the methodology used [23]. Although this earlier SAF report quantitatively measured the microbial burden in SAF, additional research was required to gain a more thorough understanding of the microbial community composition of the SAF.

In 2011, the NSA and DNA microarray methods were compared for their ability to assess relative bacterial abundance and diversity on spacecraft surfaces
[6]. Cultivable spore-forming bacterial counts derived from the NSA were extremely low for spacecraft surfaces. However, the PhyloChip generation 3 (G3) DNA microarray resolved the genetic signatures of a highly diverse suite of microorganisms in the very same sample set [6]. Samples completely devoid of cultivable spores were shown to harbor the DNA of more than 100 distinct microbial phylotypes. Furthermore, samples with higher numbers of cultivable spores did not necessarily give rise to a greater microbial diversity upon analysis with the DNA microarray [6]. The findings of this comparative study clearly demonstrated that there is not a statistically significant correlation between the cultivable spore counts obtained from a sample and the degree of bacterial diversity present [6]. Since 2011, several technological advancements emerged including extracting nucleic acids [24] and analyzing the target molecules using the next-generation sequencing (NGS) methods $[1,25]$. In the present study, a direct comparison of $16 \mathrm{~S}$ rRNA gene-targeted amplicon sequencing of the NSA isolates (spores) using Sanger sequencing with the next-generation sequencing of the $16 \mathrm{~S}$ rRNA gene (all bacteria) was attempted to understand any correlation between incidence of bacterial spore-formers and total bacterial diversity. Since it has been established that spacecraft and associated surfaces have a negligible percentage of archaea $(<1 \%)$ [26] and fungi ( $\sim 2$ to $4 \%$ ) [27], only bacterial diversity was measured during this study.

Thus, the objective of this study was to perform an in-depth analysis of the SAF facility microbial community composition over the course of 6 months, using $16 \mathrm{~S}$ rRNA gene-targeted amplicon sequencing to understand spatial and temporal relationship of the spore-forming members and bacterial diversity. Furthermore, the amplicon sequencing datasets were analyzed to understand the significance of the members of spore-formers not detected by the NSA method as well as diversity of non-spore forming bacteria. In addition, the fluorescence-activated cell sorting (FACS) and subsequent single-cell genomics (SCG) were tested for the feasibility of cultivation-independent quantification, taxonomic identification, and genome analyses of viable microorganisms in some of the low-biomass cleanroom samples. Despite several previous studies that have investigated the microbial diversity in NASA cleanrooms during various missions, this is the first-time a large number of samples were collected throughout a 6month time period to comprehend the core bacteriome of the assembly facility, in addition to assessing whether the cultivation-dependent NSA spore assay is a good proxy for predicting the total viable bacterial population. 


\section{Methods}

\section{Sample collection and processing}

Over a period of 6 months, between March 2016 and August 2016, 98 floor samples were collected during 11 sampling sessions in the SAF. The specific locations for each sampling event are given in Fig. 1. Floor samples of $1 \mathrm{~m}^{2}$ were collected using sterile, pre-moistened 9" $\times 9$ " polyester wipes (Texwipe; TX1009, NC, USA) as previously described [29]. The sampling was performed at the same location as much as possible within 2-to-3-m area over the period of 6 months. Locations were chosen at each sampling event to capture representative areas from high, medium, and low trafficked areas, as well as availability of floor space not blocked by hardware or other equipment.

Immediately after sample collection, wipe samples were deposited into sterile $500-\mathrm{mL}$ glass bottles and transferred to the lab for further processing [29, 30]. Once in the lab, 200-mL of sterile phosphate-buffered saline (PBS; pH 7.4; Sigma Aldrich, MO, USA) solution was added and vigorously shaken for $30 \mathrm{~s}$ to thoroughly mix the solution and release any collected particulates and associated microorganisms. The $200-\mathrm{mL}$ sample was then concentrated to approximately $5 \mathrm{~mL}$ using an InnovaPrep concentrating pipette with $0.45-\mu \mathrm{m}$ hollow fiber polysulfone (HFPS) concentrating pipette tips (InnovaPrep Drexel, MO, USA). The exact amount of concentrated sample was weighed on a tared scale and appropriately recorded. The concentrated samples were then used for several culture-dependent and cultureindependent assays. The microbial burden of the samples using the cultivation assays (spores and cultivable aerobic bacteria) and viability assays (adenosine triphosphate (ATP), Propidum Monoazide quantitative polymerase chain reaction (PMA-qPCR)) were performed as previously described [23].

\section{S rRNA amplicon Sanger sequencing of spore-forming isolates}

A modified NSA procedure was performed on each sample to measure the cultivable, heat shock-resistant spore population. Procedures varied slightly from the standard NSA procedure [29]. An aliquot of $425 \mu \mathrm{l}$ from the 5$\mathrm{mL}$ concentrated sample was heat shocked at $80^{\circ} \mathrm{C} \pm$ $2^{\circ} \mathrm{C}$ for $15 \mathrm{~min}$. After cooling to room temperature, 100 $\mu \mathrm{l}$ aliquots were deposited into four individual sterile petri dishes for quadruplicate measurements. Molten, sterile TSA (Thermo Fisher Scientific, Chino, CA) was then added using an aseptic standard plate pouring technique. Once solidified, plates were incubated at $32^{\circ} \mathrm{C}$ and colony forming units (CFUs) were counted after 24 h, $48 \mathrm{~h}, 72 \mathrm{~h}$, and 7 days of incubation time. A total of 130 individual colonies from the NSA were successfully stored in semi-solid TSA as stab cultures at room temperature for further analyses.

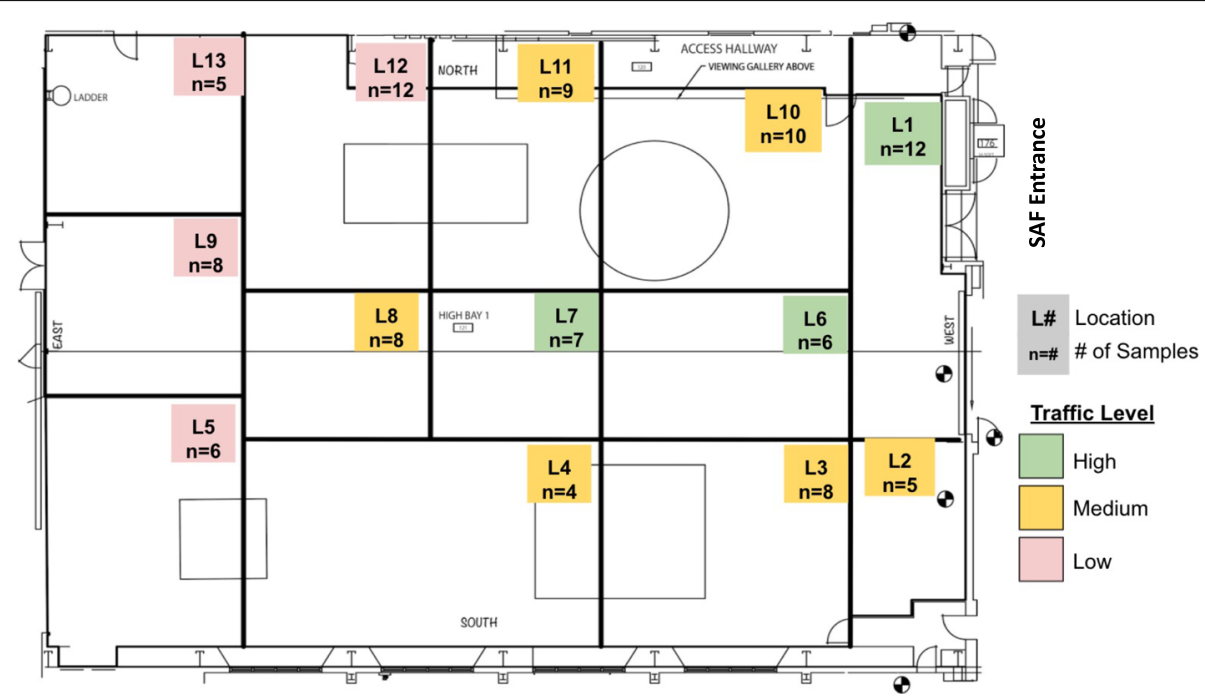

Fig. 1 Schematic of the dates and locations sampled in the Spacecraft Assembly Facility. A total of 98 samples were collected over a 6-month period from the SAF. The graph is compartmentalized into artificial section based on sample grouping and foot traffic. Each section describes the location number and number of samples collected throughout the study in a gray box. In total, there are 11 sampling dates and 13 sampling locations. The sample collection was carried out between March 2016 and August 2016, and 98 floor samples were collected during 11 sampling time periods in the JPL SAF. Total surface area of the SAF cleanroom is $921.1 \mathrm{~m}^{2}$ with controlled conditions such as temperature $\left(20 \pm 4^{\circ} \mathrm{C}\right)$, humidity (30 $\pm 5 \%$ ), stringent gowning requirements, and weekly cleaning [28]. Although SAF is capable of becoming an ISO-7 (10k) cleanroom, at the time of sampling SAF was certified as an ISO-8 (100k) cleanroom. A maximum measurement of 8287, $0.5 \mu \mathrm{m}$ particles/ $\mathrm{ft}^{3}$ and $159,5.0 \mu \mathrm{m}$ particles/ft ${ }^{3}$ were seen during the 6 months of the study. High traffic area: L1, L6, and L10; low traffic area: L5, L9, and L13. The rest of the locations had moderate traffic due to hardware assembly 
Heat-shocked isolates were grown from stab cultures on TSA overnight at $30^{\circ} \mathrm{C}$, and DNA was extracted using the Mo Bio UltraClean Microbial DNA Isolation Kit (Mo Bio Laboratories, Carlsbad, CA). The extracted DNA was used to amplify the $1.5 \mathrm{~kb} 16 \mathrm{~S}$ rRNA gene using the following primers: 27F (5'-AGA GTT TGA TCC TGG CTC AG-3') and 1492R (5'-GGT TAC CTT GTT ACG ACT T-3'). PCR conditions and Sanger sequencing parameters were followed as established before $[31,32]$. Sequence data were processed and trimmed using DNASTAR SeqMan Pro and sequences were identified using the SILVA LTP type strain SSU database (version 132). Sequences were aligned using MUSCLE [33], and a maximum likelihood phylogenetic tree was reconstructed using FastTree [34]. Novel species were determined using a $98.7 \%$ sequence similarity cutoff [35]. 16S rRNA gene sequences were deposited to GenBank under the accession numbers MW130960MW131089.

\section{PMA treatment}

To distinguish between viable and non-viable cells, samples were treated with PMA, a DNA-intercalating dye [36]. Of the concentrated $5 \mathrm{~mL}$ sample, a single $1.5-\mathrm{mL}$ aliquot was treated with $18.75 \mu \mathrm{L}$ of $2 \mathrm{mM}$ PMA (Biotium, Inc., Hayward, CA, USA). This aliquot (PMAtreated) and another $1.5 \mathrm{~mL}$ aliquot (non-PMA-treated) were vortexed and incubated in the dark for $5 \mathrm{~min}$ at room temperature. Both aliquots were then exposed to PhAST Blue-Photo activation system (GenIUL, S.L., Terrassa, Spain) for 15 min [8, 37-39]. DNA was then extracted from samples using the Maxwell DNA extraction system (Promega, Madison, WI, USA). DNA suspensions for both conditions were stored in molecular grade water $(50 \mu \mathrm{l}$ each $)$ at $-20^{\circ} \mathrm{C}$ for further analysis $[23,40]$.

\section{$16 \mathrm{~S}$ rRNA amplicon Illumina sequencing analysis}

A total of 236 samples were processed for $16 \mathrm{~S}$ rRNA sequencing. Samples were distributed across four sample types including floor wipes ( $n=196$; 98 PMA-treated, 98 PMA naive), field controls of wipes exposed to environment (in situ air) ( $n=14 ; 7$ PMA-treated, 7 PMA naive), negative controls (wipes only) ( $n=14 ; 7$ PMA-treated, 7 PMA naive), and Maxwell controls (DNA extraction reagents) ( $n=8 ; 8$ PMA naive).

The V4 region of the $16 \mathrm{~S}$ rRNA gene was amplified using the $515 \mathrm{f} / 806 \mathrm{r}$ primers and prepared for sequencing using the protocol described in the Earth Microbiome Project [41]. Libraries of 16S rRNA were prepared using equal volumes of DNA and were pooled at equal volumes post PCR to enable comparison of read counts across samples as read counts correlated to input biomass without distorting composition [1]. Final DNA concentration was $\sim 100 \mathrm{ng}$ post PCR and $\sim 1 \mathrm{ng}$ before PCR. Sequencing was performed at the UC San Diego Institute for Genomic Medicine facility using a HiSeq2500 Rapid run. Since the amount of microbial biomass (cells) [1] and subsequent DNA in the original sample correlates to the read counts post sequencing [42], it is absolutely critical to ensure equal volumetric pooling of libraries prior to sequencing, particularly when working with low biomass samples.

Raw reads were demultiplexed and quality filtered using QIIME2 v2019.10 with default parameters [43]. Quality-filtered reads were clustered into subOperational Taxonomic Units (sOTUs) using deblur [44]. A phylogenetic tree was constructed through SEPP insertion [45] with the Greengenes v13_8 as a reference backbone [46]. To identify and remove background contaminant sOTUs, sequences which were present in $100 \%$ of controls and were observed in higher absolute abundance in no-template controls than in samples were removed from the dataset. A stringent removal protocol based on presence in no-template controls alone was not used because sOTUs which are found in negatives are often a result a well-to-well contamination from nearby samples [46].

The resulting table was rarefied to 5000 counts per sample. Of the 198 primary samples (99 processed through PMA- (naïve) or PMA + (treated), 153 were successful (92 PMA-, 61 PMA treated) making up 12,825 sOTUs. Of the 38 controls, 31 had at least 5000 reads making up 983 unique sOTUs. Of those 983 sOTUs found in negative controls, 894 were found in less than $10 \%$ of the samples. Seven sOTUs, however, were present in all controls and thus deemed as putative reagent or processing contaminants.

Within sample type comparisons of read counts or alpha diversity was compared using Kruskal-Wallis test followed by Benjamini Hochberg multiple comparisons post hoc testing [47, 48]. Beta diversity comparisons were performed using unweighted and weighted UniFrac $[49,50]$. Dimensionality reduction on the UniFrac distances was performed through Principal Coordinates Analysis (PCoA). Robust Aitchison Principal component analysis (RPCA) was performed on non-rarefied data and used to produce an Aitchison distance matrix [51]. Multivariate statistical testing of drivers of distance metrics were performed using Permutational multivariate analysis of variance (PERMANOVA) [52].

Additionally, 184 out of 236 samples tested passed through the quality control measures and were used for further analysis. This included floor wipes $(n=153 ; 61$ PMA-treated, 92 PMA naive), field controls of wipes exposed to environment $(n=11 ; 4$ PMA-treated, 7 PMA naive), negative controls (wipes only) $(n=12 ; 6$ PMAtreated, 6 PMA naive), and Maxwell controls (DNA 
extraction negatives) ( $n=8 ; 8$ PMA naive). Heatmap visualizations and differential abundance comparisons between PMA- and PMA+ treated samples were performed using Calour [53] and specifically with the rank-based DA testing which utilizes a discrete false discovery rate [54].

\section{Compositional tensor factorization and log-ratios}

In the subset of PMA-treated data, compositional tensor factorization (CTF) (v. 0.0.5) was used to account for the repeated measure structure of the longitudinal measurement and the compositional nature of microbiome data [55]. Based on feature loadings produced from the unsupervised RPCA [51] and CTF [55] analyses (e.g., biplots), log-ratio of taxonomic groups determined by the lowest common ancestor were produced through Qurro [56]. The significance of log-ratios between categorical groupings was determined through a two-sided $T$ test with Bonferroni multiple-comparison correction when appropriate. For comparisons of log-ratio to continuous measurements (e.g., radius), a Pearson linear correlation test was used. All statistical testing was performed using Scipy (v. 0.14.0) [57].

\section{Effect size analysis}

In order to calculate the relative effect size of all recorded metadata within the RCPA and UniFrac ordinations, a stepwise redundancy analysis (RDA) was performed. The stepwise analysis was performed on the first three principal components of each ordination through the ordistep function in vegan v2.4-2 [58]. The ordistep function was run following the established procedure [59].

\section{Sporulation prediction}

In order to predict the possible sporulation of observed sOTUs, we performed an ancestral state reconstruction using the BacDive bacterial diversity metadatabase as the training set [60]. First, microbial strain entries with both spore formation and full $16 \mathrm{~S}$ marker gene sequence information available from the BacDive database were downloaded. The full $16 \mathrm{~S}$ sequence for each strain was downloaded with Entrez by the (National Center for Biotechnology Information) NCBI ID. Each sequence was matched exactly (i.e., 100\% identity) to the Greengenes phylogeny (v. 13_8) [61] which resulted in 9004 matches between the BacDive data and Greengenes phylogenetic tree. Next, sporulation ability prediction was performed through castor ancestral state reconstruction (v. 1.5.0) using empirical state probabilities across tips [62]. To evaluate this prediction, leave one out cross-validation was performed on each entry with sporulation information and precision-recall was evaluated, resulting in an average precision-recall of 0.82 . Finally, the observed
sOTUs from this study were predicted for the ability to produce spores using a SEPP insertion tree [45] with the sporulation-labeled Greengenes phylogenetic tree as the backbone for insertion.

\section{Source tracking}

In order to determine the source environments contributing to variation in microbial signatures within the SAF facility, microbial source tracking was used in combination with the American Gut Project (AGP) and Earth Microbiome Projects (EMP) samples as sources [41, 63]. First, the AGP and EMP datasets and accompanying metadata used for source environments were downloaded through redbiom (v. 0.3.5) [64] with the context set to Deblur [44] generated data from 16S V4 variable region Illumina sequencing data trimmed to 150 base pairs. This source data was then merged with the SAF dataset representing the tracking sinks. A feature frequency filter was applied such that all features appear with at least $0.1 \%$ prevalence across the whole dataset. This resulted in a table of 10,095 samples by 55,640 sOTUs representing ten total Empo-3 source environments. This dataset was then used for microbial source tracking with SourceTracker2 (v. 2.0.1-dev) [65] with default parameters.

\section{Single-cell genomics}

After the initial InnovaPrep concentration of the sample $(n=25)$, an aliquot was amended with $5 \%$ glycerol and 1 $\mathrm{mM}$ ethylene diamine tetraacetic acid (EDTA; final concentrations), stored at $-80^{\circ} \mathrm{C}$, and shipped on dry ice to the Bigelow Laboratory Single Cell Genomics Center (Maine, USA) for further processing. Once processing began, samples were diluted threefold with filtered (0.2$\mu \mathrm{m}$ pore size) $1 \times$ PBS and stained with RedoxSensor Green (RSG; Thermo Fisher Scientific) to identify viable cells. Individual particles with reductase activity were identified by their high green fluorescence versus red fluorescence and sorted using an inFlux Mariner (BD) sorter into 384-well plates, containing $0.6 \mu \mathrm{l}$ of Tris EDTA (TE) buffer per well, as previously described [66]. Each plate contained 317 single-cell, 64 no-cell (negative control), and three 10-cell (positive control) wells. Diameters of the sorted cells were determined using the fluorescence-activated cell sorting (FACS) light forward scatter signal, which was calibrated against cells of microscopy-characterized laboratory cultures [66]. Single-cell DNA amplification using whole genome amplification (WGA-X) and PCR-based sequencing of bacterial 16S rRNA genes were done on three microplates with cells from sample 2016-07-12:1, following previously described procedures [66]. Genomic sequencing of single amplified genomes (SAGs) from one of these plates was performed using previously described 
procedures [66]. Cell sorting and WGA-X were performed in a cleanroom environment. This workflow was previously evaluated for assembly errors using three bacterial benchmark cultures with diverse genome complexity and GC content (\%), indicating no non-target and undefined bases in the assemblies and average frequencies of mis-assemblies, indels, and mismatches per 100 kbp being $0.9,1.8$, and 4.7 [66].

\section{Results}

A schematic diagram of the SAF, where 98 samples from 13 different locations spanning 11 sampling sessions, is shown in Fig. 1. Only floor samples were collected because no flight hardware was available for this sampling campaign.

\section{Spore-forming bacterial composition}

As reported earlier, the aerobic bacterial spore burden was 36 spores per $\mathrm{m}^{2}$ which is $\sim 20 \%$ of the total heterotrophic cultivable bacterial counts [23]. Sanger sequencing of the full-length $16 \mathrm{~S}$ rRNA gene on the NSA isolates from the 98 samples resulted in 130 isolates, belonging to 16 genera and 49 species (Fig. 2). 97\% of these isolates (126/130) belonged to species of Bacillus, Brevibacillus, Cohnella, Gracilibacillus, Oceanobacillus, Paenibacillus, Psychrobacillus, Rummelibacillus, Sporosarcina, Streptomyces, Terribacillus, and Virgibacillus, which are commonly considered spore-formers. Bacillus made up the majority of this population with 73 isolates belonging to 21 species. The remaining $~ 3 \%$ of the isolates cultured from the NSA (4/130) were non-spore forming bacteria consisting of Brevibacterium luteolum, Massilia consociata, Micrococcus yunnanensis, and Staphylococcus haemolyticus. When these isolates were re-tested for their tolerance to heat, they again showed survival upon plating after heat shock at $80^{\circ} \mathrm{C}$ for 15 min.

When analyzed spatially, 36 of the 49 identified species were not ubiquitous and isolated only once in a given SAF location. The most spatially abundant isolate was Bacillus subtilis, which was found in 9 out of the 13 sampled locations in SAF (Fig. 2a). When the isolates were analyzed temporally across the 11 sampling sessions, the majority of the species $(30 / 49, \sim 61 \%)$ were isolated only once throughout the 6-month sampling period in a given sampling session. The most temporally abundant species were Virgibacillus panthothenticus (17 isolates) and B. subtilis (14 isolates), which were isolated from SAF floors on 7 individual sampling sessions (Fig. 2a) followed by Bacillus pumilus (14 isolates) that was found on 6 sampling sessions. The phylogenetic relationship amongst the cultured isolates is shown in Fig. 2a, with four isolates representing potentially novel species as they had $\leq 98.7 \%$ sequences similarity to the $16 \mathrm{~S}$
rRNA sequence of any validly described species. Of the 16 genera identified, 3 were also identified in the $16 \mathrm{~S}$ rRNA gene Illumina amplicon sequencing analysis with greater than 100 reads across all samples. Among the 3 genera identified with both methodologies one genus was a spore-former (Bacillus), while the other two (Massillia and Staphylococcus) were non-spore-forming but heat tolerant.

\section{Molecular microbial composition of the SAF}

Per sample read counts differed across sample types (Kruskal-Wallis $P<0.0001, K W=93.15)$ where PMA untreated samples had higher counts than both PMAtreated samples $(P<0.0001)$ and controls regardless of treatment [PMA- $(P<0.001)$ and PMA + controls $(P<$ 0.001)] (Fig. 3a). Microbial richness also differed across sample types (Kruskal-Wallis $P<0.0001, K W=84.31$ ) with PMA untreated samples having higher richness than PMA-treated samples, and controls $(P<0.0001)$ (Fig. 3b). Richness did not differ between PMA-treated samples or controls. The UniFrac unweighted (Fig. 3c) and weighted (Fig. 3d) analyses exhibited a differential beta diversity by PMA treatment. The heatmap representation of the features (180 out of 1250 total genera) associated with PMA treatment as calculated using the rank-based differential abundance measure in Calour, an interactive, microbe-centric analytical tool [53], is depicted in Fig. $3 \mathrm{e}$, and it is evident that PMA treatment removed most of the dead microorganisms. When sequences were detected and compared from both PMA and non-PMA samples of a given sampling date and location, an average of $\sim 33 \%$ of the OTU richness was determined to be from live cells or present due to background contamination in processing.

Changes in 16S rRNA gene amplicon sequencing composition were assessed through PCoA on unweighted and weighted UniFrac in addition to PCA on Aitchison distances produced from RPCA. PMA treatment and the collection timepoint led to significant differences in microbiota (Fig. 3f) and contributed to the majority of the total explained effect size in ordinations (Table S1). These shifts in beta-diversity by PMA treatment are partially attributed to a decrease in the log-ratio of Pseudomonadales (order) relative to Bacilli (class) (Fig. 3g). The log-ratio of Pseudomonadales (order) relative to $\mathrm{Ba}$ cilli (class) was used to understand the microbial diversity shift because reads associated with Pseudomonadales were not increased in the sampled environment, while Bacilli reads were enriched by the entrance versus the interior of the facility.

To account for the repeated measure structure of the data (i.e., time), CTF was used to explore microbial community changes between SAF locations. CTF but not RPCA, weighted, or unweighted -UniFrac beta-diversity 


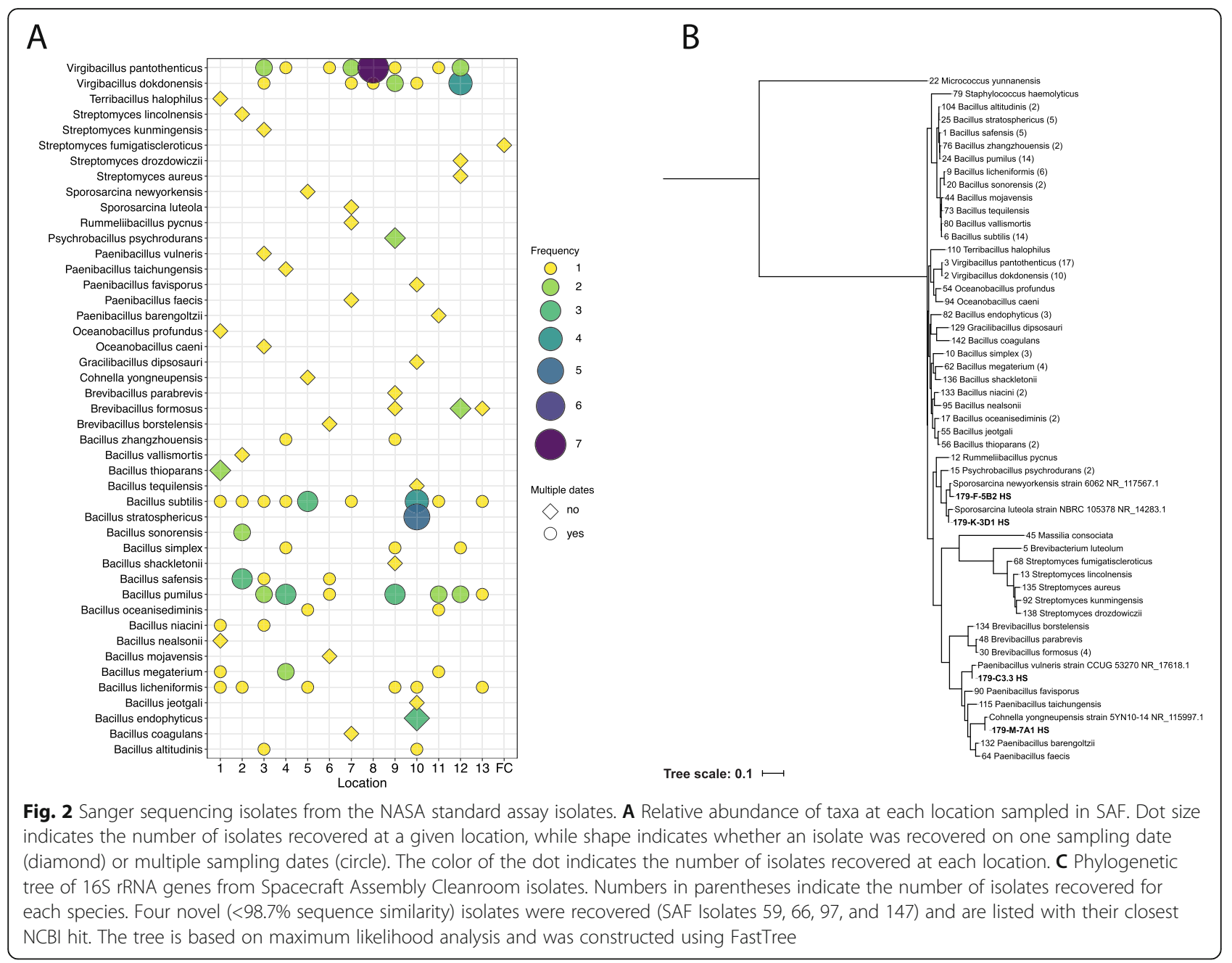

distances revealed significant differences between SAF room location (Table S2). The differences in rooms were explained partially by the log-ratio of Rhizobiales (Proteobacteria) to Bacillales (Firmicutes) (Fig. S1a; Fig. $\mathrm{S} 1 \mathrm{~b})$. As the radius from the facility entrance increased, a decrease in the log-ratio of Rhizobiales (Proteobacteria) to Bacillales (Firmicutes) was also observed. We further hypothesized, given the known sporulation ability of Bacillales that the resilience as spores could possibly be driving the observed variation between SAF room location. Both Rhizobiales and Bacillales are often found in the environment and so could easily be brought in from external sources. But Rhizobiales are non-sporeforming and are likely non-viable far from the entrance, thus, the change in the ratio between the two was noticed and computed.

Using ancestral state reconstruction with the Deutsche Sammlung von Mikroorganismen und Zellkulturen (DSMZ) BacDive database, sporulation ability was predicted through the SEPP insertion tree (Average Precision=0.83; Fig. S2). The location mean log-ratio of predicted non-spore forming and spore forming microbes correlated with the radial distance from the entrance of the SAF facility by Pearson correlation $(r=0.61$, $P=0.027$; Fig. $4 \mathrm{a})$ showing that the number of sporeformers compared to non-spore-formers decreases the further away from the entrance. Microbial source tracking of each room over time using the AGP and EMP datasets of sources revealed possible sources of SAF contaminant bacteria. As the radius from the entrance increased, the contribution from animal surfaces (AGP; skin) decreased and the contribution from soil (EMP; non-saline) sources increased (Fig. 4b). Non-saline surfaces (EMP) also contributed as a source environment but remained stable except for a spike at a radius of 800 pixels.

A detailed description and interpretation of all facilities compared are beyond the scope of this report, but we provide a brief comparison of the present time-series SAF data with previous 100-swab KatharoSeq JPL-SAF data, one neonatal intensive care unit, an abalonerearing facility, and three International Space Station 

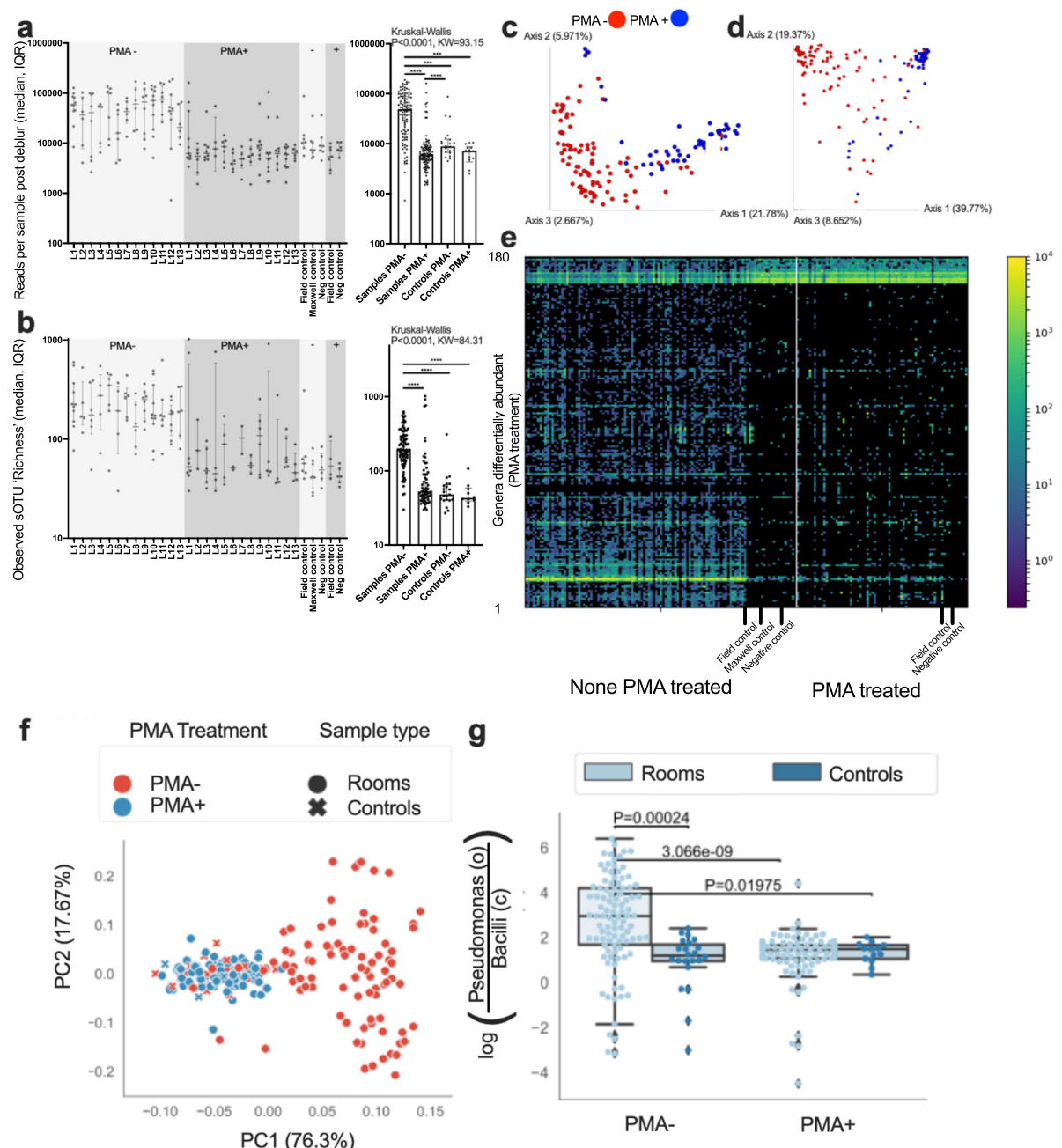

Fig. 316 rRNA sequencing results (A-B). Distribution of $\mathbf{A}$ reads and $\mathbf{B}$ richness (alpha diversity) of $16 \mathrm{~S}$ rRNA measured across the 13 SAF locations grouped by PMA treatment. Microbial composition of live vs dead cell communities as determined using PMA treatment (C-E). Microbial community beta diversity driven strongly by PMA treatment for $\mathbf{C}$ unweighted UniFrac and D weighted UniFrac (PMA- "red" and PMA+ treated "blue" samples). E Heatmap representation of the features (180 out of 1250 total genera) associated with PMA treatment as calculated using the differential abundance measure in Calour with controls labeled for reference. Comparison of microbial community composition between PMA live vs. dead treatment (F-G). Robust Aitchison PCA (RPCA) compare between PMA treated (blue) and untreated (red) SAF rooms (circles) and controls (ex) (F). Log-ratio of lowest common ancestor aggregated Pseudomonadales (order) and Bacilli (class) compared by PMA treatment between rooms (light blue) and controls (dark blue) (G). $P$ values obtained from pairwise $t$ tests with Bonferroni multiple comparisons correction

(ISS) environmental data in characterizing a range of low-biomass environments and relating them to one another (Fig. 4c, d) [1]. Within each of the five environments, the extremely clean abalone-rearing facility exhibited entirely different microbial profile with the rest of the facility floors. Even though all other facilities look similar with reference to microbial diversity (Fig. 4c), detailed characterization of the weighted Unifrac analysis showed differential microbial diversity composition on neonatal intensive care unit and ISS surfaces when compared to JPL-SAF time-series samples. When compared with previous JPL KatharoSeq study sampled 100 swabs on one day of the same facility, this present JPL time- series data points differed in their microbial community composition (Fig. 4d).

In the PMA-treated samples with greater than 100 total reads across all samples, a total of 46 non-spore forming genera and 8 spore forming genera were identified (Fig. 5). Across the non-control PMA-treated samples, the reads broke down into $4.28 \%$ (NSA sporeformers), 9.66\% (non-NSA Spore-formers), and 86.05\% (non-Spore-formers). The ten most predominant genera identified in PMA-treated samples were Sphingobium, Pseudomonas, Caulobacter, Clostridium, Acinetobacter, Azospira, Bacillus, Deinococcus, Acidovorax, and Arthrobacter. Of the ten most prominent overall genera, only 
a

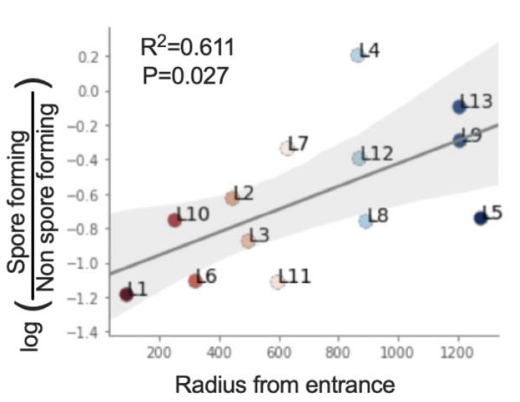

C Unweighted Unifrac (closed ref $150 \mathrm{nt}$ )

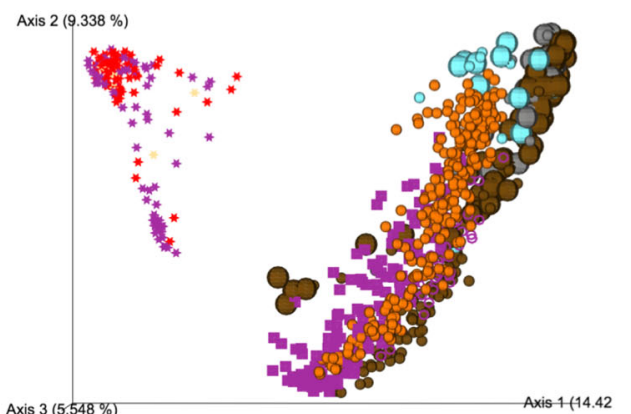

b

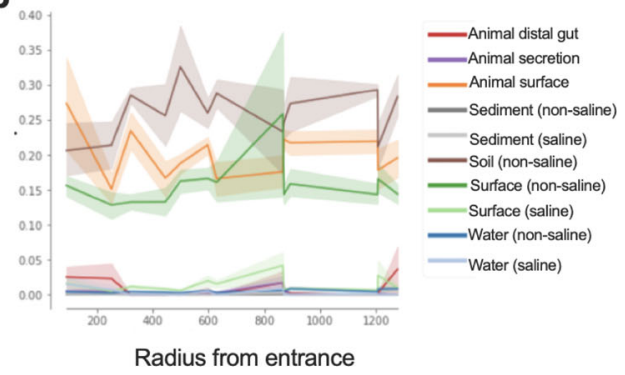

d

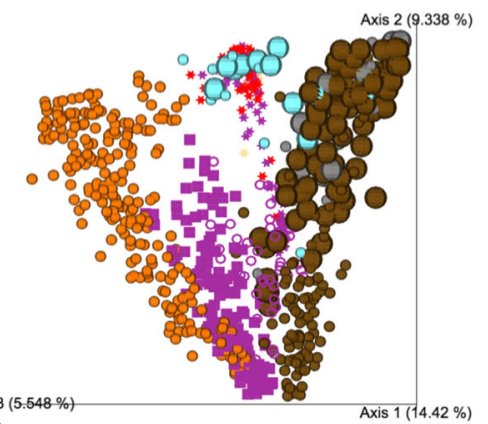

Katharoseq study

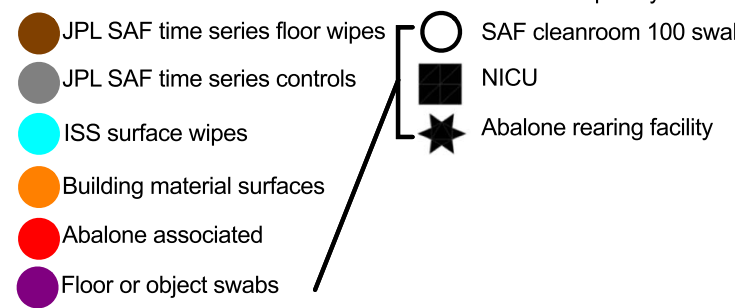

Fig. 4 Microbial differentiation across SAF locations differs by radial distance from facility entrance (A-B). (x-axes) Linear regression plot of logratio of ancestral state predicted sporulating and non-sporulating bacteria ( $y$-axis) by radial distance from entrance (A). Proportion of contribution from AGP and EMP empo-3 sources ( $y$-axis) across radius from entrance (B). Pearson correlation used for linear comparison and error bars represent the standard error of the mean. $\mathbf{C}$ Unweighted $(\mathbf{C})$ and weighted (D) microbiome meta-analysis of JPL SAF time series compared to other built environments (JPL SAF 100 swab study, International Space Station, building materials study, abalone rearing facility, NICU hospital study).

two (Clostridium and Bacillus) were spore-formers. The eight spore forming genera were Clostridium, Bacillus, Actinoplanes, Geobacillus, Actinomyces, Dolichospermum, Microbispora, and Mycobacterium.

The Bacillus and Actinomyces genera were the only two NSA spore-formers detected in the PMA samples. Bacillus was the most temporally frequent NSA sporeformer, which had more reads than Actinomyces in sampling sessions $2,3,4,5,6,7,10$, and 11 . Alternatively, a total of six non-NSA spore-formers (Actinoplanes, Clostridium, Dolichospermum, Geobacillus, Microbispora, Mycobacterium) were detected in the PMA samples. Geobacillus was the most temporally abundant nonNSA spore-former with the most non-NSA sporeformer reads in the 1st sampling sessions. A total of 46 non-spore-formers were detected in the PMA samples. The most abundant non-spore genera varied for each sampling session; however, Acinetobacter did have the most reads in 2nd and 4th sampling sessions.

Comparison of NSA spores, non-NSA spore-formers, and non-spore-formers did not exhibit any consistent microbial population pattern (Fig. 5a). However, sampling sessions 4,6 , and 8 had higher reads of NSA spores compared to non-NSA-spore-formers. In every other sampling session, non-NSA-spore reads were greater than NSA spore reads. Additionally, reads of non-spore-former were greater than the combined reads of NSA spore and non-NSA-spore categories for every sampling session. The heatmap of the amplicon sequencing reads computed with the reads of NSA spores and non-NSA spores in Fig. 5b, c clearly shows that reads associated with spores were less than 100 reads in controls (except in 1 field control) and were most abundant when samples collected during 8th sampling sessions. Spatial 


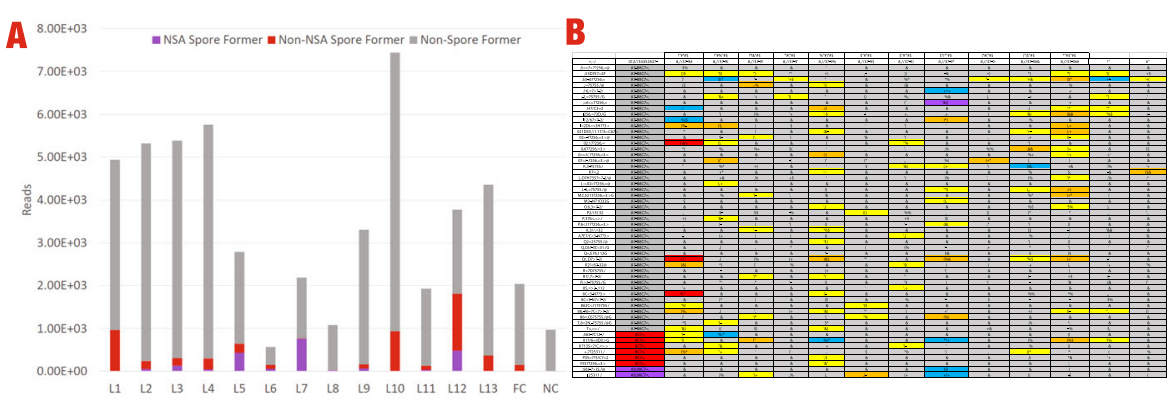

C

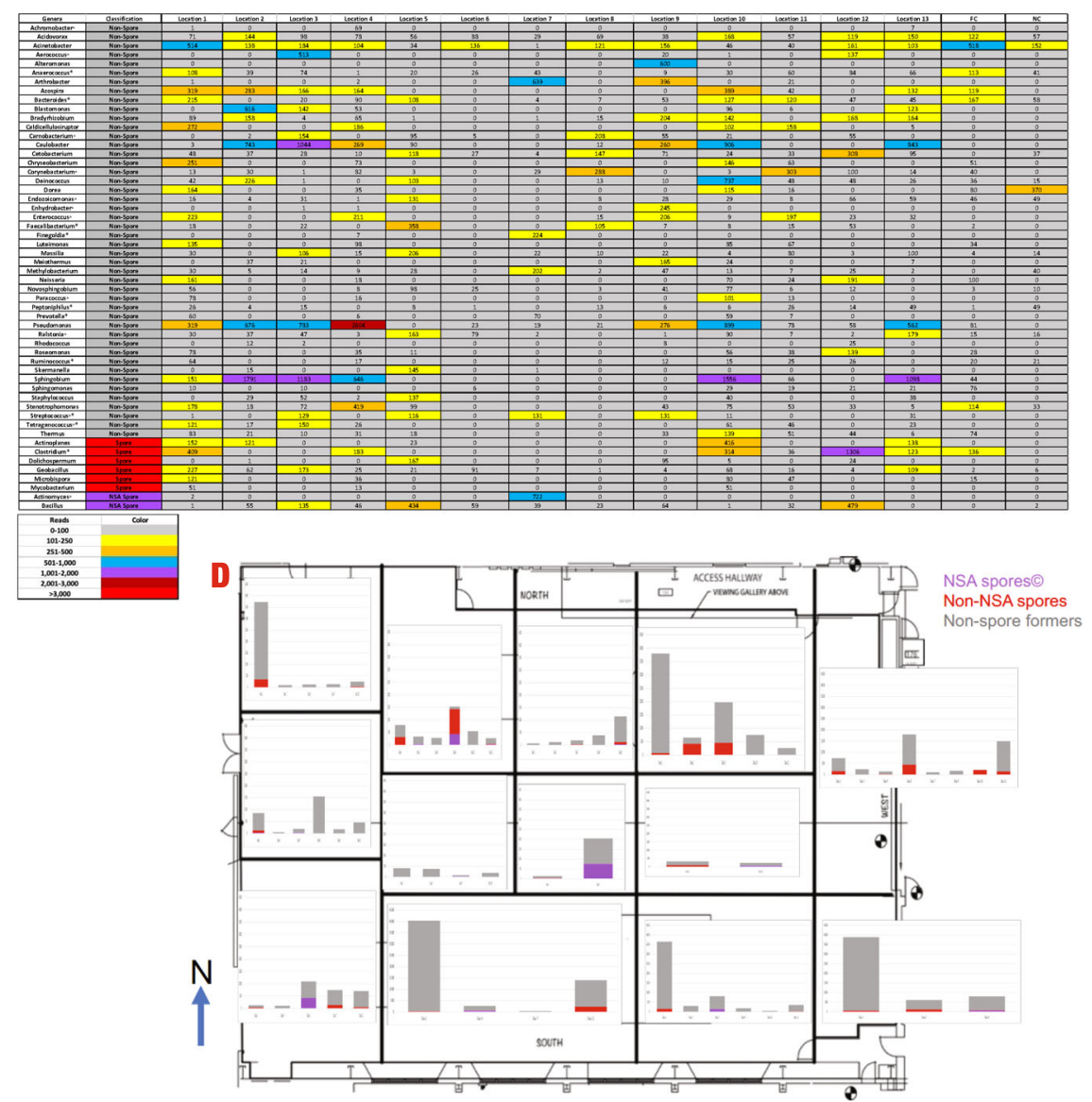

Fig. 5 A Total PMA reads per location of genera with greater than 100 total reads across all samples. Genera are described as non-spore(gray), non-NSA spore(red), and NSA(purple). Field Control (FC) and Negative Control (NC) composition are also displayed. B Temporal heatmap of PMAtreated reads of genera with greater than 100 total reads across all samples. Genera are described as non-spore(gray), non-NSA spore(red), and NSA(purple). ( = facultative, ${ }^{*}=$ anaerobic) $C$ Spatial heatmap of PMA-treated reads of genera with greater than 100 total reads across all samples. Genera are described as non-spore(gray), non-NSA spore(red), and NSA(purple). D Spatial PMA reads by sampling location. Individual bars represent a single sample collected at a given location. Genera are described as non-spore (gray), non-NSA spore (red), and NSA (purple)

and temporal distributions of the viable microbial population (PMA-treated samples) over 13 locations are depicted in Fig. 5d. Locations \#5, 7, and 8 showed a higher presence of spores detectable by the NSA method than non-NSA spores. A higher incidence of non-NSA spore-formers was noticed in other locations, confirming that the NSA method misses the majority of these spore-formers which might need other optimal cultivation conditions for their growth. In addition, it cannot be ruled out that these spore-forming microorganisms might have been in the vegetative cell state and were killed during the $80^{\circ} \mathrm{C} ; 15$ min heat-shock procedure of the NSA method. It is also noteworthy to mention that all of these locations had more non-spore-forming members when compared to spore-formers.

Bacillus was the most spatially abundant NSA sporeformer, with its highest total NSA spore-former reads in Location 12. Geobacillus was the most spatially frequent 
non-NSA spore-former, with the most non-NSA sporeformer reads from Location 1 . The most spatially abundant non-spore-former was Sphingobium, with high reads in Location 10 (Fig. 5c).

No NSA spore-formers were detected in the PMA field controls. Only Bacillus was detected in the PMA negative controls ( 2 reads). The most abundant nonNSA spore-formers in controls was Clostridium in PMA field controls (136 reads) and Geobacillus in PMA negative controls (6 reads). The most abundant non-sporeformers were Acinetobacter in PMA field controls (518 reads) and Dorea in PMA negative controls (370 reads) (Fig. 5b, c).

\section{Single-cell genome sequencing}

As described previously in Hendrickson et al. (2017), 25 samples were analyzed via FACS to estimate the number of viable microorganisms. Viable cells, as identified by FACS, were randomly sorted into 384-well microplates, with 317 individual cells collected from each sample tested (Fig. 6a). For this study, sample 2016-07-12 Location \#1 was chosen for proof of principal of the singlecell genomics analysis and was the only sample that was analyzed with all three methods (NSA, amplicon sequencing, and single-cell genome sequencing). This sample was chosen because it was located closer to the entrance of the cleanroom and also documented to have higher viable bioburden $\left(8.8 \times 10^{5}\right.$ viable cells per $\left.\mathrm{m}^{2}\right)$ to analyze. Furthermore, the average spore counts on this sample was 35 spores per $\mathrm{m}^{2}$ of the surface area, giving the highest spore to viable microorganisms ratio of 12,091 [23]. A combination of genomic sequencing and PCR screens of the 16S rRNA gene of one of the microplates identified taxonomic affiliations of 78 of the 317 generated SAGs (Fig. 6b). Among the identified SAGs, 72 were identified as Acinetobacter, 3 as Sphingomonads, 2 as Paracoccus, and 1 as Cupriavidus. Additional genera, identified by the $16 \mathrm{~S}$ rRNA gene PCR screens of two additional SAG microplates, included Microvirga, and Novosphingobium were also found in the SCG method. The size, florescence, and identity of RedoxSensor Green-positive cells are shown in Fig. 6b.

\section{Discussion}

From the Viking mission in 1975 until the most recent Perseverance mission in 2020, NASA has utilized spore counts as a proxy to estimate the viable microbial burden on spacecraft destined for landing on Mars. However, due to the nature of the assay, only those microbes that can survive heat shock and grow on TSA plates are accounted for. With advancements in next-generation sequencing and single-cell genomics, we are better equipped to detect/monitor the inherent microbiome of spacecraft assembly cleanrooms that can help inform policies and protocols to minimize bioburden populations able to survive interplanetary travel and contribute to potential forward contamination risk of spacecraft hardware. The analysis provided by these molecular methods can also help determine whether these new technologies should now be used by NASA as a better measure of cleanliness or whether the established NSA is a suitable proxy for estimating the potential microbial contamination of spacecraft components. In this study, Sanger sequencing of NSA isolates along with amplicon sequencing and single-cell genomics allowed us to perform a temporal and spatial analysis of the microbial community composition over the 6-month period of collected samples. Additional shogun metagenomic analysis to infer functional pathways was not feasible given the low biomass samples from SAF $\left(<1\right.$ pg per $\left.\mathrm{m}^{2}\right)$ which were far less than the amount required ( 100 pg) for this additional analysis.

A previous study demonstrated that NSA and a DNA microarray assays did not show a statistically significant correlation between the cultivable spore counts obtained from a sample and the degree of bacterial diversity present [6]. DNA microarrays require a priori information of the microorganism and thus underestimate the correlation of spores and microbial diversity present in a given sample. It was also reported by these authors that the NSA spore-formers were not detected in the DNA microarray analysis due to the poor DNA extraction during that time.

While the NSA is aimed to be a proxy method to identify biological cleanliness on spacecraft surfaces, it can detect only a select and limited representation of the microbial population, specifically spore-formers cultivable under certain conditions [9, 17, 20, 23]. This was reflected in our results as $\sim 97 \%$ of isolates were identified as spore forming bacteria. The other $3 \%$ of isolates were non-spore-formers but appeared to withstand $80^{\circ} \mathrm{C}$ for $15 \mathrm{~min}$. The spore population was $3.6 \times 10^{1} \mathrm{CFU}$ per $\mathrm{m}^{2}$ of the SAF surface area which constituted $\sim 20 \%$ of the total cultivable population [23]. A previous study that utilized ATP, PMAqPCR, and FACS-based viable microbial burden analyses estimated the NSA was $10^{2}-10^{4}$ fold less than the total bioburden present [23].

The NSA's ability to identify a limited microbial population was apparent when compared with the 16S rRNA gene amplicon sequencing analysis that identified 1250 genera after PMA treatment (Fig. 3c-e). Although the $16 \mathrm{~S}$ rRNA gene amplicon sequencing analysis detected 1250 viable genera, only 54 genera were detected with $>100$ total reads. Of the top 10 genera with the most reads, only two were reported to form spores. This contrasted with the $97 \%$ spore forming isolates identified in 

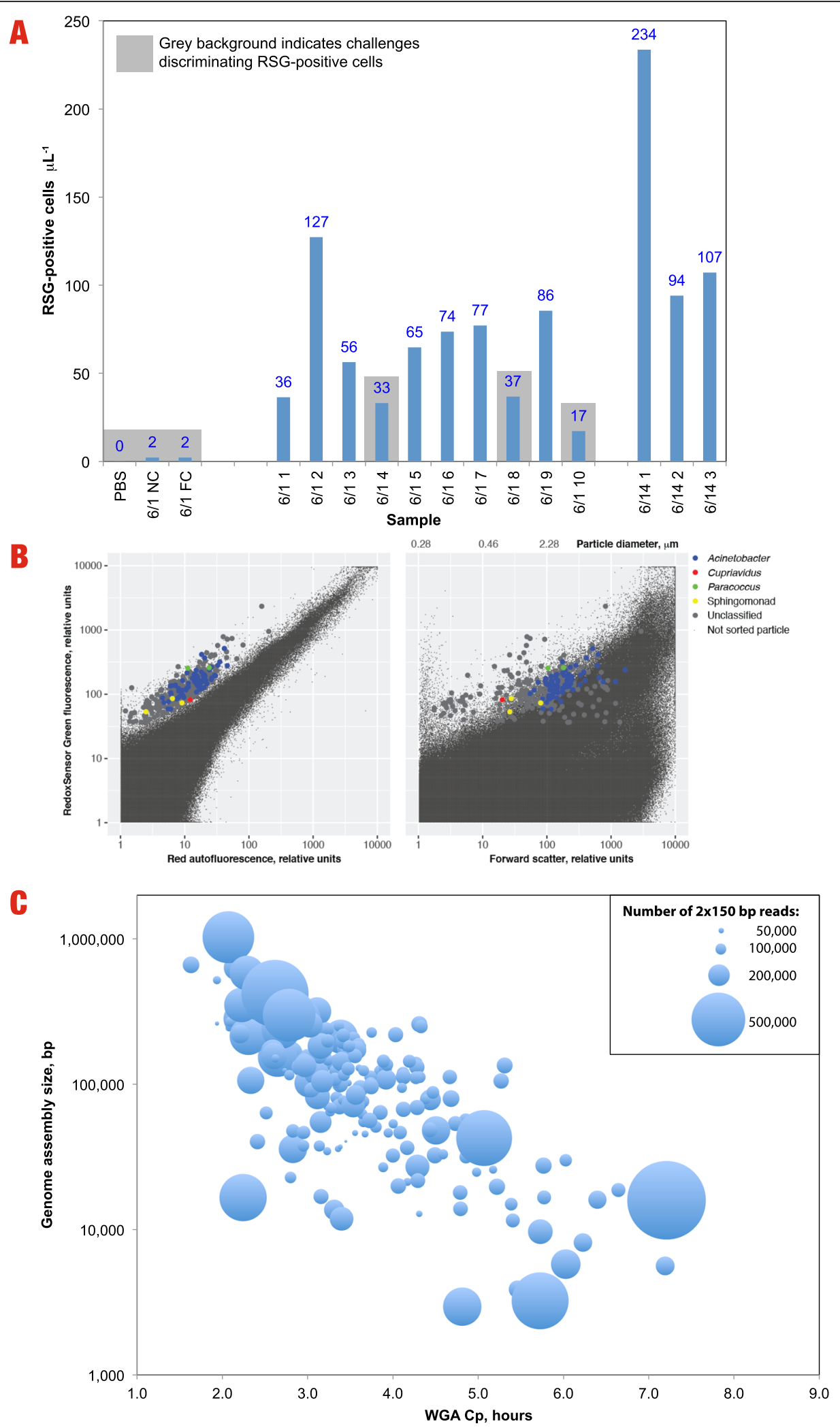

Fig. 6 A RSG-positive cells per uL identified in various samples processed with fluorescent-activated cell sorting. B Flow cytometric characteristics and taxonomic affiliations of individual, RedoxSensor Green-positive cells from sample 2016-07-12-1A. C Genome assembly size by whole genome amplification Cp (hours) 
with NSA approach and confirmed that spore-forming microorganisms constituted a fraction of total bacterial population. Several spore-forming bacterial species that were dominant (e.g., Geobacillus, a thermophilic species) were not detected by NSA method because of its mesophilic cultivation conditions. Additionally, the OTUs with $>100$ reads included 8 spore forming genera whereas 12 spore forming genera were isolated via NSA. This might be due to the phylogenetic analysis resolution where $1.5 \mathrm{~kb}$ length of $16 \mathrm{~S}$ rRNA gene fragments was used for identifying NSA isolates versus $~ 150$-bp length of V4 variable region for amplicon sequencebased OTU calling. The V4 variable region of all 12 species isolated via NSA (Bacillus, Brevibacillus, Gracilibacillus, Oceanobacillus, Paenibacillus, Rummeliibacillus, and Virgibacillus) was conserved, hence it was not possible to resolve the inter-genus speciation and amplicon sequencing that might have identified them as Bacillus. However, sequences of the members belong to other spore-forming genera including Bacillus (aerobes), Clostridium (anaerobes), Actinoplanes (oligotrophs), Geobacillus (thermophiles), Actinomyces (anaerobes), Dolichospermum (cyanobacteria), Microbispora (endophyte), and Mycobacterium (slow-grower) were retrieved via the amplicon sequencing method. Identification of these non-NSA spore-forming genera was possible due to the high variation in V4 variable region. Hence, if the diversity of spore-forming microorganisms is the main goal, when amplicon sequencing is employed, the use of a universal house keep gene like gyrB [67] or functional genes like spore photoproduct B subunit [68] or sporulation genes [69] should be examined. The universal gyrB primer has been successfully used to differentiate the members of the genus Bacillus cereus-anthracis clade where full length $16 \mathrm{~S}$ rRNA gene $(\sim 1.5 \mathrm{~kb})$ showed $100 \%$ sequence similarities [67].

The temporal and spatial analysis of the amplicon sequences analysis showed variations in relative abundance of the genera that are NSA spore-formers (aerobic mesophilic members), non-NSA spore-formers (all spore-forming members exhibiting growth irrespective of cultivable conditions), and non-spore forming bacteria. Overall, the variations in reads showed that the non-spore-formers made up a significant percentage $(\sim 86 \%)$ of the reads in PMA-treated samples, while the NSA spore-formers and non-NSA spore-formers made up much smaller percentages or $\sim 4 \%$ and $\sim 10 \%$, respectively. Temporally, these percentages varied from samples collected at various sampling session intervals ( 15 days), represented by a large range for non-spore-formers (64-99\%), NSA spore-formers (0 to 35\%), and non-NSA sporeformers (1 to 22\%). The percentages varied widely from one sampling session to another; however, a similar percentage breakdown of populations was observed between the 10th and 11th sampling session: non-spore-former $(89 \rightarrow 90 \%)$, NSA spore-former $(1 \rightarrow 2 \%)$, and non-NSA spore-former $(10 \rightarrow 8 \%)$. The largest percentage of each population was observed on different time periods with non-spore-formers on 9th sampling (99\%), NSA spore-formers on 6th sampling (35\%), and non-NSA spore-formers on 2nd sampling time $(22 \%)$. Similar variations were observed spatially across the samples. Non-spore-formers made up the majority of reads at locations ranging from 52 to $96 \%$ with the largest percent of the population in location 2. NSA spore-formers had a range of 0 to $35 \%$ with the largest percentage found in location 7 . The non-NSA spore-formers had a range of 0 to $35 \%$ with the largest percentage found in location 12. In fact, location 12 had the highest overall spore percentage (NSA + non-NSA spore-formers) at $48 \%$. Such a dynamic temporal and spatial distribution of all kinds of microorganisms might be due to the human traffic during this study.

When looking at raw reads, the three most abundant reads were detected on 1st sampling time on March 2, 2016, with three non-spore forming genera: Caulobacter (3805 reads), Pseudomonas (5121 reads), and Sphingobium (6111 reads). The most reads for non-NSA spore-former belong to Clostridium (995 reads) on 8th sampling period (June 28, 2016) and the most reads for a NSA spore-former were Actinomyces (722 reads) on this sampling session as well. Even though the cleanroom temperature was controlled, the higher 16S rRNA copy numbers from June 28 to Aug 162016 as measured by qPCR [23] might be potentially correlated to the outside temperature which was warmer in June to August $2016\left(\sim 90^{\circ} \mathrm{F}\right)$ when compared to March $2016\left(\sim 70^{\circ} \mathrm{F}\right)$ and is not statistically significant (data not shown).

Among the JPL-SAF cleanroom, locations 4, 7, 10, 11, and 12 had high human activities due to the assembly processes pertaining to the Mars 2020 mission subsystems. Since all personnel enter through location 1, despite thorough cleaning by the professional janitorial service, replenishment of microbial populations was predicted when compared to other locations and might be attributed to the microbial shedding by human. FACS exhibited higher counts $\left(1 \times 10^{6}\right.$ per $\left.\mathrm{m}^{2}\right)$ of viable cells but PMA-qPCR copy numbers $\left(5 \times 10^{4}\right.$ per $\left.\mathrm{m}^{2}\right)$ were not much higher in location \#1 when compared to other locations [23]. The higher FACS counts compared to qPCR copy numbers might be due to potential loss during DNA extraction before amplicon sequencing whereas cells were counted in FACS method. Pseudomonas had the most non-spore forming reads with 2604 reads at location 4 . The non-NSA spore-former reads of 
Clostridium (1306) were high at location 12, and the NSA spore-former Actinomyces (722) reads were highest at location 7. Since locations 5, 9, and 13 were far from human activities, fewer microbial reads were observed. The cleaning procedure was the same for all the locations where janitorial crew maintain the cleanliness of the JPL-SAF as per established protocol; however, due to the presence of hardware in locations $4,7,10$, and 12 , access to these locations might have been limited for cleaning.

Additionally, we observed variations in the spore to non-spore ratio based on proximity to the entrance of SAF (Fig. 4a). At the entrance in SAF location 1, this ratio was $\sim 13$ spore-formers to 1 non-spore-former. This ratio decreased on the samples collected farther from the entrance. Only one sampling site (location 4) showed an approximate equal ratio between spore-formers and non-spore-formers. On average, all other locations had a higher percentage of spore-formers compared to nonspore-formers. This change to spore to non-spore ratio could potentially indicate more hardy conditions near the entrance due to cleaning frequency. A previous study in the SAF compared microbial communities of 100 locations within the facility at a single time point [1]. When comparing this study to the previous SAF samples and additional built environments, it was clear that PMA treatment (and thus live vs. dead cells) in the SAF facility was a major discriminatory driver to community composition (Fig. 4c). Samples from the SAF facility clustered more closely to samples taken from the ISS compared to samples from earthly settings such as a hospital and building environments (Fig. 4c). Other built environments like JPL-SAF and the ISS, which have much more controlled access compared to unlimited access gained by the patients in hospitals and workers in office buildings might explain why JPL-SAF closely resembles the ISS with reference to microbial diversity profile. Even then, when the Unifrac analysis (Fig. 4d) was computed, a clear difference among ISS and JPLSAF time-series data points was noticed.

Although the scope of this project only allowed for one sample to be analyzed using single-cell genomics, it did show differences from the other two analysis methodologies. The analyzed sample, 2016-07-12, location 1, identified 5 genera, all of which are described as nonspore forming microorganisms. Acinetobacter, Sphingobium, and Paracoccus species were found in both SCG and amplicon sequencing. However, members of the genera Pseudomonas, Caulobacter, and Azospira were found only in the amplicon sequencing approach whereas members of Cupriavidus, Microvirga, and Novosphingobium were found only in the SCG method. The FACS-SCG approach was able to quantify, determine cell sizes and recover genomic sequences of viable

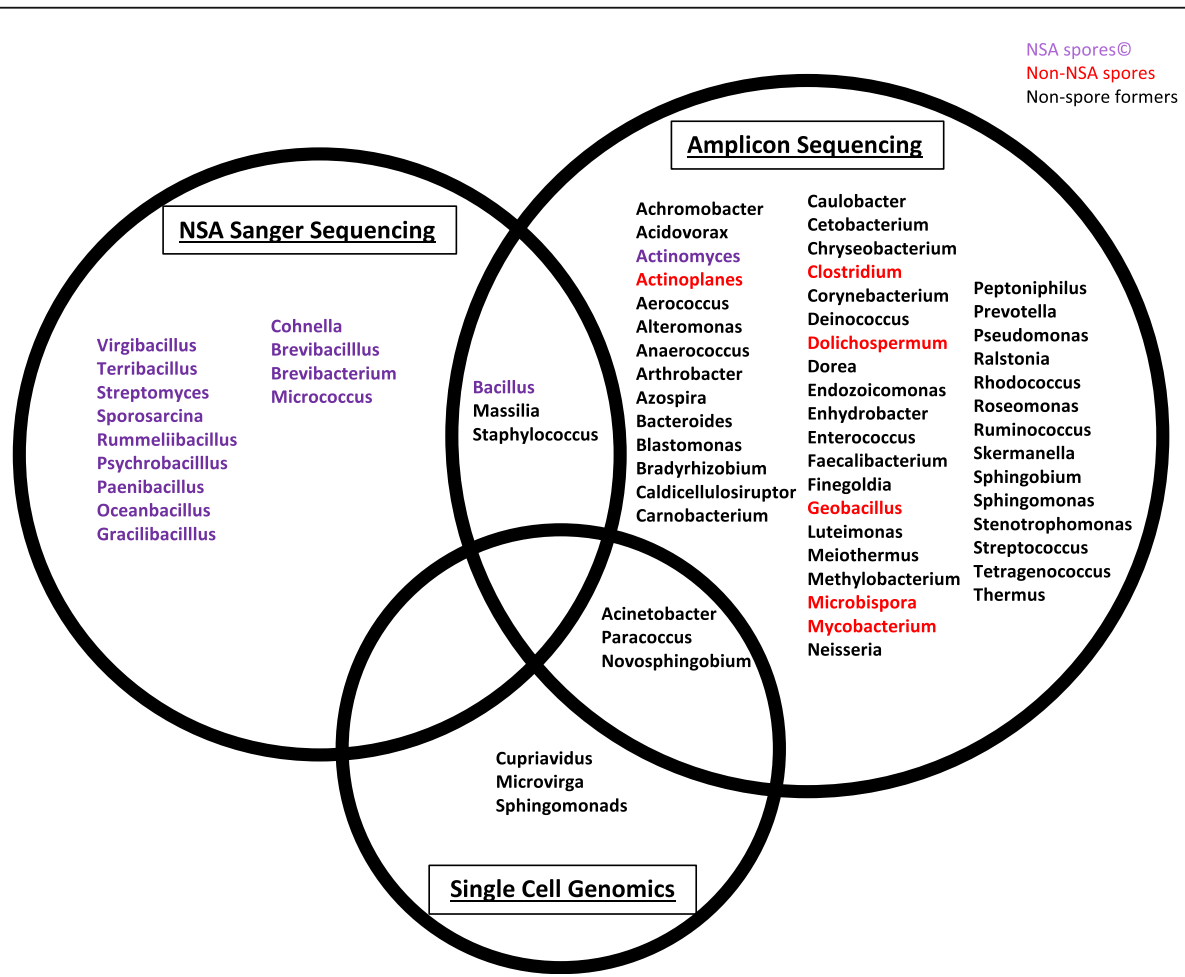

Fig. 7 Venn diagram of identified genera in the three different methodologies used; Sanger sequencing, amplicon sequencing, and single-cell genomics. Purple text indicates NSA spore-formers and red text indicates all non-NSA spore formers 
microbial cells from most of the analyzed SAF samples, without the need for cultivation.

In this study, we observed 6 genera that were identified in two different methodologies and 64 genera only identified with one methodology (Fig. 7), many of which have been previously found in spacecraft cleanrooms $[2$, $7,9,17,19,20,70-73]$. Only 3 genera profiled via amplicon sequencing were also present in the SCG sequencing. This might be attributed to only one sample being analyzed by SCG or from a PCR bias where a low number of DNA fragments were only amplified in amplicon sequencing method. Although Fig. 7 shows the genera identified in each methodology, it is difficult to completely compare the Sanger sequencing of culture-based isolates with the above molecular techniques because of inherent selective process of the NSA and cultivation compared to the other molecular methods that used PMA-treated DNA.

\section{Conclusion}

The SAF is a unique artificial environment with oligotrophic conditions that result in a unique microbial population. All three methodologies provide a unique perspective of the total microbial population, and this study has shown that observed bioburden abundance and diversity are heavily affected by choice of analysis method. To understand the overall microbial population, multiple methodologies should be considered to obtain a more complete picture of the microbial composition. The utilization of both the NSA and molecular methods is necessary to provide the scientific community with a more complete picture of the bioburden fractions that may survive interplanetary travel (desiccation, vacuum, low-nutrient, etc.) and proliferate in the extraterrestrial environmental conditions (anaerobes, psychrophiles, radiation resistant microorganisms, etc.) while also linking those findings to the long bioburden history documenting the bioburden that could be present on robotic missions.

\section{Supplementary Information}

The online version contains supplementary material available at https://doi. org/10.1186/s40168-021-01159-x.

Additional file 1: Figure S1. Comparison of microbial community composition between SAF location. First two-principle components of the Compositional Tensor Factorization (CTF) biplot, dots colored by most prevalent phyla being Rhizobiales (Proteobacteria) (red) and Bacillales (Fimicutes) (blue), arrows colored by SAF location radial distance from entrance $(\mathbf{A})$. Log-ratio of lowest common ancestor grouped taxonomic groupings in the biplot correlated to radial distance from the SAF entrance (B). Figure S2. Seven contaminants removed from analysis which were present in $100 \%$ of the controls and had a positive ratio compared to control:PMA- samples. Table S1. Effect size in ordinations from PMA treatment and the collection timepoint. Table S2. Sample size, number of groups, test statistic, and P-value of weighted UniFrac, Unweighted UniFrac, RPCA, and CTF.

\section{Acknowledgements}

Part of the research described in this publication was carried out at the Jet Propulsion Laboratory, California Institute of Technology, under a contract with NASA. Researchers associated with Biotechnology and Planetary Protection Group at JPL are acknowledged for their facility support. The authors would like to thank Aleksandra (Ola) Checinska Sielaff, Nitin Singh, Ganesh Malli-Mohan, Patrick Lundgren, Courtney Carlson, for sampling the JPL-SAF and help rendered by Taguhi Arakelian and Percy Moore for cleanroom sampling coordination is valued. We appreciated James N. Benardini, Moogega Stricker, Doug Bernard, and Fuk Lee for financial support and directions. We thank the staff of the Bigelow Laboratory for Ocean Sciences Single Cell Genomics Center (SCGC) for the generation of single-cell genomic data. (c) 2020 California Institute of Technology. All rights reserved. Government sponsorship acknowledged.

\section{Disclaimer}

This manuscript was prepared as an account of work sponsored by the NASA, an agency of the US Government. The US Government, NASA, California Institute of Technology, Jet Propulsion Laboratory, and their employees make no warranty, expressed or implied, or assumed any liability or responsibility for the accuracy, completeness, or usefulness of information, apparatus, product, or process disclosed in this manuscript, or represents that its use would not infringe upon privately held rights. The use of, and references to any commercial product, process, or service does not necessarily constitute or imply endorsement, recommendation, or favoring by the US Government, NASA, California Institute of Technology, or Jet Propulsion Laboratory. Views and opinions presented herein by the authors of this manuscript do not necessarily reflect those of the US Government, NASA, California Institute of Technology, or Jet Propulsion Laboratory, and shall not be used for advertisements or product endorsements.

\section{Authors' contributions}

$\mathrm{KV}$ coordinated with $\mathrm{RH}$ in designing the concept, executed the study, implemented the project, involved in the data analyses, and wrote the manuscript. RH performed the DNA extraction of the collected samples, contributed to the data analysis, interpretation, and drafted the manuscript. CU helped analyze the data, write the paper, and assisted in the study design. HA extracted the DNA from spore-forming isolates, analyzed Sanger sequences, generated appropriate figures, and wrote corresponding sections. JM generated 165 amplicon sequences, and CM performed computational analysis and statistical interpretation of 16S rRNA amplicon data along with RK. RS oversaw single-cell genomics, and associated data analyses were performed by RS. The authors read and approved the final manuscript.

\section{Funding}

The research was carried out at the Jet Propulsion Laboratory, California Institute of Technology, under a contract with the National Aeronautics and Space Administration (80NM0018D0004). This research was supported by the JPL Mars Program Office project. Additional funding sources included NSF grants OIA-1826734 and OCE-1335810 and NASA grant 18-EXO18-0048 to RS. The funders had no role in study design, data collection and interpretation, the writing of the manuscript, or the decision to submit the work for publication.

\section{Availability of data and materials}

The data presented in this manuscript are available in the NCBI Sequence Read Archive under the accession no. PRJEB40954. The 16S rRNA sequences of the isolates were deposited in the NCBI GenBank under accession no: MW130960 to MW131089. Associated 165 feature tables are publicly available in Qiita (qiita.ucsd.edu) [73] under study ID 10689 and analysis code can be found at https://github.com/knightlab-analyses/SAF-PP-JPL.

\section{Declarations}

Ethics approval and consent to participate Not applicable.

\section{Consent for publication}

All authors that participated in this study have reviewed the results, read the final manuscript, and gave their consent for publication. 


\section{Competing interests}

All other authors declare that they have no competing interests.

\section{Author details}

'Biotechnology and Planetary Protection Group, Jet Propulsion Laboratory, California Institute of Technology, Pasadena, USA. ${ }^{2}$ Marine Biology Research Division, Scripps Institute of Oceanography, University of California San Diego, La Jolla, CA, USA. ${ }^{3}$ Center for Microbiome Innovation, University of California San Diego, La Jolla, CA, USA. ${ }^{4}$ Bioinformatics and Systems Biology Program, University of California San Diego, La Jolla, CA, USA. ${ }^{5}$ Bigelow Laboratory for Ocean Sciences, East Boothbay, ME, USA.

Received: 15 December 2020 Accepted: 13 August 2021 Published online: 04 December 2021

\section{References}

1. Minich JJ, Zhu Q, Janssen S, Hendrickson R, Amir A, Vetter R, et al. KatharoSeq enables high-throughput microbiome analysis from lowbiomass samples. mSystems. 2018;3(3). https://doi.org/10.1128/mSystems. 00218-17.

2. Vaishampayan P, Osman S, Andersen G, Venkateswaran K. High-density 165 microarray and clone library-based microbial community composition of the Phoenix spacecraft assembly clean room. Astrobiology. 2010;10(5):499508. https://doi.org/10.1089/ast.2009.0443.

3. La Duc MT, Osman S, Vaishampayan P, Piceno Y, Andersen G, Spry JA, et al. Comprehensive census of bacteria in clean rooms by using DNA microarray and cloning methods. Appl Environ Microbiol. 2009;75(20):6559-67. https:// doi.org/10.1128/aem.01073-09.

4. Link L, Sawyer J, Venkateswaran K, Nicholson W. Extreme spore UV resistance of Bacillus pumilus isolates obtained from an ultraclean spacecraft assembly facility. Microb Ecol. 2004;47(2):159-63. https://doi.org/10.1007/ s00248-003-1029-4.

5. Venkateswaran K, Satomi M, Chung S, Kern R, Koukol R, Basic C, et al. Molecular microbial diversity of a spacecraft assembly facility. Syst Appl Microbiol. 2001;24(2):311-20. https://doi.org/10.1078/0723-2020-00018.

6. Cooper M, La Duc MT, Probst A, Vaishampayan P, Stam C, Benardini JN, et al. Comparison of innovative molecular approaches and standard spore assays for assessment of surface cleanliness. Appl Environ Microbiol. 2011; 77(15):5438-44. https://doi.org/10.1128/aem.00192-11.

7. Mahnert A, Vaishampayan P, Probst AJ, Auerbach A, Moissl-Eichinger C, Venkateswaran $\mathrm{K}$, et al. Cleanroom maintenance significantly reduces abundance but not diversity of indoor microbiomes. PLoS One. 2015;10(8): e0134848. https://doi.org/10.1371/journal.pone.0134848.

8. Vaishampayan P, Probst AJ, La Duc MT, Bargoma E, Benardini JN, Andersen GL, et al. New perspectives on viable microbial communities in low-biomass cleanroom environments. ISME J. 2013;7(2):312-24. https://doi.org/10.1038/ismej.2 012.114

9. La Duc MT, Dekas A, Osman S, Moissl C, Newcombe D, Venkateswaran K. Isolation and characterization of bacteria capable of tolerating the extreme conditions of clean room environments. Appl Environ Microbiol. 2007;73(8): 2600-11. https://doi.org/10.1128/AEM.03007-06.

10. Favero MS. Microbiologic assay of space hardware. Environ Biol Med. 1971; $1(1): 27-36$.

11. Foster TL, Winans $L$ Jr. Psychrophilic microorganisms from areas associated with the Viking spacecraft. Appl Microbiol. 1975;30(4):546-50. https://doi. org/10.1128/am.30.4.546-550.1975.

12. Puleo JR, Fields ND, Bergstrom SL, Oxborrow GS, Stabekis PD, Koukol R. Microbiological profiles of the Viking spacecraft. Appl Environ Microbiol. 1977;33(2):379-84. https://doi.org/10.1128/aem.33.2.379-384.1977.

13. Puleo JR, Oxborrow GS, Fields ND, Hall HE. Quantitative and qualitative microbiological profiles of the Apollo 10 and 11 spacecraft. Appl Microbiol. 1970;20(3):384-9. https://doi.org/10.1128/am.20.3.384-389.1970.

14. Puleo JR, Fields ND, Moore B, Graves RC. Microbial contamination associated with the Apollo 6 spacecraft during final assembly and testing. Space Life Sci. 1970;2(1):48-56. https://doi.org/10.1007/BF00928955.

15. Puleo JR, Oxborrow GS, Fields ND, Herring CM, Smith LS. Microbiological profiles of four Apollo spacecraft. Appl Microbiol. 1973;26(6):838-45. https:// doi.org/10.1128/am.26.6.838-845.1973.

16. Venkateswaran K, Kempf M, Chen F, Satomi M, Nicholson W, Kern R. Bacillus nealsonii sp. nov., isolated from a spacecraft-assembly facility, whose spores are gamma-radiation resistant. Int J Syst Evol Microbiol. 2003;53(Pt 1):16572. https://doi.org/10.1099/ijs.0.02311-0.

17. Ghosh S, Osman S, Vaishampayan P, Venkateswaran K. Recurrent isolation of extremotolerant bacteria from the clean room where phoenix spacecraft components were assembled. Astrobiology. 2010;10(2):325-35. https://doi. org/10.1089/ast.2009.0396.

18. Benardini JN, La Duc MT, Ballou D, Koukol R. Implementing Planetary Protection on the Atlas V fairing and ground systems used to launch the Mars Science Laboratory. Astrobiology. 2014;14(1):33-41. https://doi.org/10.1089/ast.2013.1011.

19. La Duc MT, Nicholson W, Kern R, Venkateswaran K. Microbial characterization of the Mars Odyssey spacecraft and its encapsulation facility. Environ Microbiol. 2003:5(10):977-85. https://doi.org/10.1046/j.1462-2920.2003.00496.x.

20. Moissl-Eichinger C, Auerbach AK, Probst AJ, Mahnert A, Tom L, Piceno Y, et al. Quo vadis? Microbial profiling revealed strong effects of cleanroom maintenance and routes of contamination in indoor environments. Sci Rep. 2015;5(1). https://doi.org/10.1038/srep09156.

21. Lax S, Smith DP, Hampton-Marcell J, Owens SM, Handley KM, Scott NM, et al. Longitudinal analysis of microbial interaction between humans and the indoor environment. Science. 2014;345(6200):1048-52. https://doi.org/1 $0.1126 /$ science. 1254529 .

22. NRC. Preventing the Forward Contamination of Europa. Washington, D.C: Task Group on the Forward Contamination of Europa, Space Studies Board, National Research Council, National Academies Press; 2006. p. 1-41.

23. Hendrickson R, Lundgren P, Mohan G, Urbaniak C, Benardini J, Venkateswaran K. Comprehensive measurement of microbial burden in nutrient-deprived cleanrooms 47th International Conference on Environmental Systems. 2017; ICES-2017-177.

24. Urbaniak C, Wong S, Tighe S, Kumar A, Liu B, Parker C, et al. Validating an automated nucleic acid extraction device for omics in space using whole cell microbial reference standards. Front Microbiol. 2020;11:1909. https://doi. org/10.3389/fmicb.2020.01909.

25. Singh NK, Wood JM, Karouia F, Venkateswaran K. Succession and persistence of microbial communities and antimicrobial resistance genes associated with International Space Station environmental surfaces. Microbiome. 2018;6(1):214. https://doi.org/10.1186/s40168-018-0609-y.

26. MoissI C, Bruckner JC, Venkateswaran K. Archaeal diversity analysis of spacecraft assembly clean rooms. ISME J. 2008;2(1):115-9 http://www.nature. com/ismej/journal/v2/n1/suppinfo/ismej200798s1.html.

27. La Duc MT, Vaishampayan P, Nilsson HR, Torok T, Venkateswaran K. Pyrosequencing-derived bacterial, archaeal, and fungal diversity of spacecraft hardware destined for Mars. Appl Environ Microbiol. 2012;78(16): 5912-22; AEM.01435-12 [pii]. https://doi.org/10.1128/AEM.01435-12.

28. Hendrickson R, Lundgren P, Malli-Mohan GB, Urbaniak C, Benardini JN, Venkateswaran K. Comprehensive measurement of microbial burden in nutrient-deprived cleanrooms. In: 47th International Conference on Environmental Systems; ICES-2017-177. Charleston: ICES; 2017.

29. NASA. Handbook for the Microbiological Examination of Space Hardware, NASA-HDBK-6022. Washington, DC: National Aeronautics and Space Administration; 2010.

30. Venkateswaran K, La Duc MT, Vaishampayan P. Genetic inventory task: final report, JPL Publication 12-12. In., vol. 1 and 2. Pasadena: Jet Propulsion Laboratory, California Institute of Technology; 2012. p. 1-117.

31. Lane DJ. 16S/23S rRNA sequencing. In: Stackebrandt $E_{1}$ Goodfellow M, editors. Nucleic acid techniques in bacterial systematics. New York: Wiley; 1991. p. 115-63.

32. Turner S, Pryer KM, Miao VP, Palmer JD. Investigating deep phylogenetic relationships among cyanobacteria and plastids by small subunit rRNA sequence analysis. J Eukaryotic Microbiol. 1999;46(4):327-38.

33. Edgar RC. MUSCLE: a multiple sequence alignment method with reduced time and space complexity. BMC Bioinformatics. 2004;19(5):113. https://doi. org/10.1186/1471-2105-5-113.

34. Price MN, Dehal PS, Arkin AP. FastTree 2--approximately maximumlikelihood trees for large alignments. PLoS One. 2010;5(3):e9490. https://doi. org/10.1371/journal.pone.0009490.

35. Yarza P, Yilmaz P, Pruesse E, Glöckner FO, Ludwig W, Schleifer K-H, et al. Uniting the classification of cultured and uncultured bacteria and archaea using 16S rRNA gene sequences. Nat Rev Microbiol. 2014;12(9):635-45. https://doi.org/10.1038/nrmicro3330. https://www.nature.com/articles/ nrmicro3330\#supplementary-information.

36. Nocker A, Camper AK. Novel approaches toward preferential detection of viable cells using nucleic acid amplification techniques. FEMS Microbiol Lett. 2009;291(2):137-42. https://doi.org/10.1111/j.1574-6968.2008.01429.x. 
37. Nocker A, Richter-Heitmann T, Montijn R, Schuren F, Kort R. Discrimination between live and dead cellsin bacterial communities from environmental water samples analyzed by 454 pyrosequencing. Int Microbiol. 2010;13(2): 59-65. https://doi.org/10.2436/20.1501.01.111.

38. Rawsthorne H, Dock CN, Jaykus LA. PCR-based method using propidium monoazide to distinguish viable from nonviable Bacillus subtilis spores. Appl Environ Microbiol. 2009;75(9):2936-9. https://doi.org/10.1128/AEM. 02524-08.

39. Nocker A, Sossa-Fernandez P, Burr MD, Camper AK. Use of propidium monoazide for live/dead distinction in microbial ecology. Appl Environ Microbiol. 2007;73(16):5111-7. https://doi.org/10.1128/AEM.02987-06

40. Venkateswaran K, Vaishampayan P, Benardini JN 3rd, Rooney AP, Spry JA Deposition of extreme-tolerant bacterial strains isolated during different phases of Phoenix spacecraft assembly in a public culture collection. Astrobiology. 2014;14(1):24-6. https://doi.org/10.1089/ast.2013.0978.

41. Thompson LR, Sanders JG, McDonald D, Amir A, Ladau J, Locey KJ, et al. A communal catalogue reveals Earth's multiscale microbial diversity. Nature. 2017;551(7681):457-63. https://doi.org/10.1038/nature24621.

42. Cruz G, Christoff A, Vakter de Oliveira L. Equivolumetric protocol generates library sizes proportional to total microbial load in $16 \mathrm{~s}$ amplicon sequencing. Front Microbiol. 2021;12(425). https://doi.org/10.3389/fmicb.2 021.638231.

43. Bolyen E, Rideout JR, Dillon MR, Bokulich NA, Abnet CC, Al-Ghalith GA, et al. Reproducible, interactive, scalable and extensible microbiome data science using QIIME 2. Nat Biotechnol. 2019;37(8):852-7. https://doi.org/10.1038/s41 587-019-0209-9.

44. Amir A, McDonald D, Navas-Molina JA, Kopylova E, Morton JT, Xu Z, et al. Deblur rapidly resolves single-nucleotide community sequence patterns. mSystems. 2017;2(2):e00191-16. https://doi.org/10.1128/mSystems.00191-16.

45. Janssen S, McDonald D, Gonzalez A, Navas-Molina JA, Jiang L, Xu ZZ, et al. Phylogenetic placement of exact amplicon sequences improves associations with clinical information. mSystems. 2018;3(3):e00021-18. https://doi.org/10.1128/mSystems.00021-18.

46. Minich JJ, Sanders JG, Amir A, Humphrey G, Gilbert JA, Knight R. Quantifying and understanding well-to-well contamination in microbiome research. mSystems. 2019;4(4):e00186-19.

47. Kruskal WH, Wallis WA. Use of ranks in one-criterion variance analysis. J Am Stat Assoc. 1952;47(260):583-621. https://doi.org/10.1080/01621459.1952.104 83441.

48. Benjamini Y, Hochberg Y. Controlling the false discovery rate: a practical and powerful approach to multiple testing. J Royal Stat Soc Series B. 1995; 57(1):289-300. https://doi.org/10.1111/j.2517-6161.1995.tb02031.x.

49. Lozupone C, Knight R. UniFrac: a new phylogenetic method for comparing microbial communities. Appl Environ Microbiol. 2005;71(12):8228-35. https://doi.org/10.1128/AEM.71.12.8228-8235.2005.

50. Louzupone C, Lladser ME, Knights D, Stombaugh J, Knight R. UniFrac: an effective distance metric for microbial community comparison. ISME J. 2010; 5(2):169-72. https://doi.org/10.1038/ismej.2010.133.

51. Martino C, Morton JT, Marotz CA, Thompson LR, Tripathi A, Knight R, et al. A novel sparse compositional technique reveals microbial perturbations. mSystems. 2019;4(1):e00016-9. https://doi.org/10.1128/mSystems.00016-19.

52. Anderson MJ. A new method for non-parametric multivariate analysis of variance. Aust Ecol. 2008;26(1):32-46. https://doi.org/10.1046/j.1442-9993.2 001.01070.x

53. Xu ZZ, Amir A, Sanders J, Zhu Q, Morton JT, Bletz MC, et al. Calour: an interactive, microbe-centric analysis tool. mSystems. 2019;4(1):e00269-18. https://doi.org/10.1128/mSystems.00269-18.

54. Jiang L, Amir A, Morton J, Heller R, Arias-Castro E, Knight R, et al. Discrete false-discovery rate improves identification of differentially abundant microbes. mSystems. 2017;2(6):e00092-17. https://doi.org/10.1128/mSystems. 00092-17

55. Martino C, Shenhav L, Marotz CA, Armstrong G, McDonald D, Vázquez-Baeza $Y$, et al. Context-aware dimensionality reduction deconvolutes gut microbial community dynamics. Nat Biotechnol. 2020;39(2):165-8. https://doi.org/10.1 038/s41587-020-0660-7.

56. Fedarko MW, Martino C, Morton JT, González A, Rahman G, Marotz CA, et al. Visualizing 'omic feature rankings and log-ratios using Qurro. bioRxiv. 2019: 2019.12.17.880047. https://doi.org/10.1101/2019.12.17.880047.

57. Virtanen P, Gommers R, Oliphant TE, Haberland M, Reddy T, Cournapeau D, et al. SciPy 1.0: fundamental algorithms for scientific computing in Python. Nat Methods. 2020;17(3):261-72. https://doi.org/10.1038/s41592-019-0686-2.
58. Oksanen J, Guillaume Blanchet FG, Friendly M, Kindt R, Legendre P, McGlinn $\mathrm{D}$, et al. vegan: Community Ecology Package. R package version 2.5-6. https://CRAN.R-project.org/package=vegan. 2019.

59. Falony $G$, Joossens $M$, Vieira-Silva S, Wang J, Darzi $Y$, Faust $K$, et al. Population-level analysis of gut microbiome variation. Science. 2016 352(6285):560-4. https://doi.org/10.1126/science.aad3503.

60. Reimer LC, Vetcininova A, Carbasse JS, Söhngen C, Gleim D, Ebeling C, et al BacDive in 2019: bacterial phenotypic data for high-throughput biodiversity analysis. Nucleic Acids Res. 2019;47(D1):D631-D6. https://doi.org/10.1093/na r/gky879.

61. McDonald D, Price MN, Goodrich J, Nawrocki EP, DeSantis TZ, Probst A, et al. An improved Greengenes taxonomy with explicit ranks for ecological and evolutionary analyses of bacteria and archaea. ISME J. 2012;6(3):610-8. https://doi.org/10.1038/ismej.2011.139.

62. Louca S, Doebeli M. Efficient comparative phylogenetics on large trees. Bioinformatics. 2017;34(6):1053-5. https://doi.org/10.1093/bioinformatics/ btx701.

63. McDonald D, Hyde E, Debelius JW, Morton JT, Gonzalez A, Ackermann G, et al. American gut: an open platform for citizen science microbiome research. mSystems. 2018;3(3):e00031-18. https://doi.org/10.1128/mSystems. 00031-18

64. McDonald D, Kaehler B, Gonzalez A, DeReus J, Ackermann G, Marotz C, et al redbiom: a rapid sample discovery and feature characterization system. mSystems. 2019;4(4):e00215-9. https://doi.org/10.1128/mSystems.00215-19.

65. Knights D, Kuczynski J, Charlson ES, Zaneveld J, Mozer MC, Collman RG, et al. Bayesian community-wide culture-independent microbial source tracking. Nat Methods. 2011;8(9):761-3. https://doi.org/10.1038/nmeth.1650.

66. Stepanauskas R, Fergusson EA, Brown J, Poulton NJ, Tupper B, Labonté JM, et al. Improved genome recovery from individual, uncultured microbial cells and viral particles. 2017.

67. La Duc MT, Satomi M, Agata N, Venkateswaran K. gyrB as a phylogenetic discriminator for members of the Bacillus anthracis-cereus-thuringiensis group. J Microbiol Meth. 2004;56(3):383-94. https://doi.org/10.1016/j. mimet.2003.11.004.

68. Rebeil R, Sun Y, Chooback L, Pedraza-Reyes M, Kinsland C, Begley TP, et al. Spore photoproduct lyase from Bacillus subtilis spores is a novel iron-sulfur DNA repair enzyme which shares features with proteins such as class III anaerobic ribonucleotide reductases and pyruvate-formate lyases. J Bacteriol. 1998;180(18):4879-85. https://doi.org/10.1128/JB.180.18.4879-4 885.1998.

69. Galperin MY, Mekhedov SL, Puigbo P, Smirnov S, Wolf YI, Rigden DJ. Genomic determinants of sporulation in Bacilli and Clostridia: towards the minimal set of sporulation-specific genes. Environ Microbiol. 2012;14(11): 2870-90. https://doi.org/10.1111/j.1462-2920.2012.02841.x.

70. Moissl-Eichinger C, Pukall R, Probst AJ, Stieglmeier M, Schwender P, Mora M, et al. Lessons learned from the microbial analysis of the Herschel spacecraft during assembly, integration, and test operations. Astrobiology. 2013;13(12): 1125-39. https://doi.org/10.1089/ast.2013.1024.

71. Smith SA, Benardini JN, Anderl D, Ford M, Wear E, Schrader M, et al. Identification and characterization of early mission phase microorganisms residing on the Mars Science Laboratory and assessment of their potential to survive mars-like conditions. Astrobiology. 2017;17(3):253-65. https://doi. org/10.1089/ast.2015.1417

72. Moissl C, Osman S, La Duc MT, Dekas A, Brodie E, DeSantis T, et al. Molecular bacterial community analysis of clean rooms where spacecraft are assembled. FEMS Microbiol Ecol. 2007;61(3):509-21. https://doi.org/10.1111/ j.1574-6941.2007.00360.x.

73. Vaishampayan P, Miyashita M, Ohnishi A, Satomi M, Rooney A, La Duc MT, et al. Description of Rummeliibacillus stabekisii gen. nov., sp. nov. and reclassification of Bacillus pycnus Nakamura et al. 2002 as Rummeliibacillus pycnus comb. nov. Int J Syst Evol Microbiol. 2009;59(Pt 5):1094-9. https:// doi.org/10.1099/ijs.0.006098-0.

\section{Publisher's Note}

Springer Nature remains neutral with regard to jurisdictional claims in published maps and institutional affiliations. 